\title{
Clinical Audit on Service Provider Hand Hygiene at Neonatal ICU of Assiut University Childern Hospital
}

\author{
ZEINAB M. MOHEY EL-DIN, M.D.; NAFISA H. REFAT, M.D. and JOHN N. AZMY, M.Sc. \\ The Department of Pediatrics, Faculty of Medicine, Assiut University, Assiut, Egypt
}

\begin{abstract}
Background: Hand hygiene is considered the simplest and most effective measure to prevent cross-transmission of microorganisms and hospital acquired infection.

Aim of Study: To evaluate service providers hand hygiene in Neonatal Intensive Care Unit of Assiut University Childern Hospital within six months.

Patients and Methods: The target population in this study were service providers in Neonatal Intensive Care Unit in Assiut University Childern Hospital including physicians and nurses. An observational checklist guidelines was used to assess service provider hand hygiene at NICU within six months between september 2016 and february 2017.

Results: The total number of hand hygiene settings evaluated were 1118 including 891 hand wash (482 nurses, 409 physicians) and 227 hand rub (119 before endo-tracheal intubation and 108 before umbilical catheter insertion).
\end{abstract}

Key Words: Hand hygiene - Service provider - Hand hygiene preparations - Hand wash - Hand rub - Physicians-Nurses.

\section{Introduction}

PREVENTION of nosocomial infection is the responsibility of all indidviduals and services providing health care. Everyone must work cooperatively to reduce the risk of infection for patients and staff. This includes personnel providing direct patient care, management and training of health workers. Infection control programmes are effective provided they are comprehensive and include surveillance and prevention activites, as well as staff training. There must be also effective support at the national and regional levels (Ducel et al., reference [1]).

The hands of healthcare workers are major transmitters of infection and even after only minor contact with the patient or equipment, pathogens

Correspondence to: Dr. John N. Azmy, The Department of Pediatrics, Faculty of Medicine, Assiut University, Assiut, Egypt have been recovered from the hands of healthcare workers as long as two and a half hours after the initial contact (Teare et al., reference [2]).

There is significant increase in bacterial counts on the hands of healthcare workers after just two minutes of contact with an infant's skin during routine care, and even higher counts during respiratory care (Pessoa-Silva et al., reference [3]).

Several studies have identified that artificial and long nails are more likely to be colonized with bacteria than short natural nails (Foca et al., reference [4]).

(Pratt et al., reference [5]) recommended that finger nails should be kept short, clean and free from nail polish.

Hand hygiene is considered the simplest and most effective measure to prevent cross-transmission of microorganisms and Hospital Acquired Infection (HAI). Unfortunately, professionals appear to have difficulties in performing hand hygiene procedures and compliance below $50 \%$ has been repeatedly reported. Non-compliance with hand hygiene practices and the effect of promotional programmes have often been studied in pediateric and neonatal settings. In brief, the use of an alcohol-based handrub solution is now considered as the gold standard for hand hygiene. It should be emphasised that when contact with body fluids is anticipated, gloves should be worn (PosafyBarbe et al., reference [6]).

Evidence supporting the use of one hand hygiene product over the other is unclear. There was no difference in infection rates between the use of a $61 \%$ ethanol and emollient containg hand rub (12.1 infections/1000 patient days) and antiseptic soap containing $2 \%$ chlorhexidine $(9.5$ infection/ 1000 patient days) in NICU (Larson et al., reference [7]). 
The use of gloves is recommended for the protection of the healthcare worker, and to reduce the cross-transfer of micro-organisms between patients. While gloves can protect staff from contamination, commensal and pathogenic bacteria accumulate on gloves during care episods, facilitating the transmission of pathogen (Pessoa-Silva et al., reference [3]).

The use of gloves dose not replace hand washing. Gloves become easily contaminated and hands are then contaminated during the removal of gloves (Pratt et al., reference [5]).

Despite all information, studies and education demonstrating the importance of handwashing in infection control, healthcare workers frequently do not wash their hands adequately (Widmer, reference [8], Fendler et al., reference [9]).

\section{The aim of this study is:}

To evaluate service provider hand hygiene in NICU of Assiut University Childern Hospital within six months.

\section{Patients and Methods}

The target population were service providers in Neonatal Intensive Care Unit at Assiut University Childern Hospital including physicians and nurses. The total number were 1118 procedures including 891 hand wash (482 nurses, 409 physicians) and 227 hand rub. This study was done within six months during the period between september 2016 and february 2017.

For hand wash, five indications were applied in this study. They were:

- Before touching patient.

- Before aseptic procedure.

- After body fluid exposure.

- After touching patient.

- After touching patient surroundings.

For handrub, two indications were applied in this study. They were:

- Endo-tracheal intubation.

- Umblical catheter insertion.

\section{Results}

The total number of hand washing practice were 1118 including 891 hand wash (482 nurses, 409 physicians) and 227 hand rub (119 before Endo-tracheal intubation and 108 before Umbilical catheter insertion) which is shown in the following Tables $(1,2)$.
Table (1): Total hand washing practice studied in Neonatal ICU of AUCH.

\begin{tabular}{lclc}
\hline Indication & Nurse & Physician & Total \\
\hline Before touching patient & 119 & 170 & 289 \\
Before aseptic procedure & 101 & $\begin{array}{l}\text { Not done } \\
\text { by physicians }\end{array}$ & 101 \\
& & 58 & 148 \\
After body fluid exposure & 90 & 58 & 199 \\
After touching patient & 89 & 110 & 154 \\
After touching patient surrounding & 83 & 71 & 891 \\
\hline Total & 482 & 409 & \\
\hline
\end{tabular}

Table (2): Total physicians handrub practice studied in Neonatal ICU of AUCH.

\begin{tabular}{lc}
\hline Indication & Number \\
\hline Before endo-tracheal intubation & 119 \\
Before umbilical catheter insertion & 108 \\
\hline Total & 227 \\
\hline
\end{tabular}

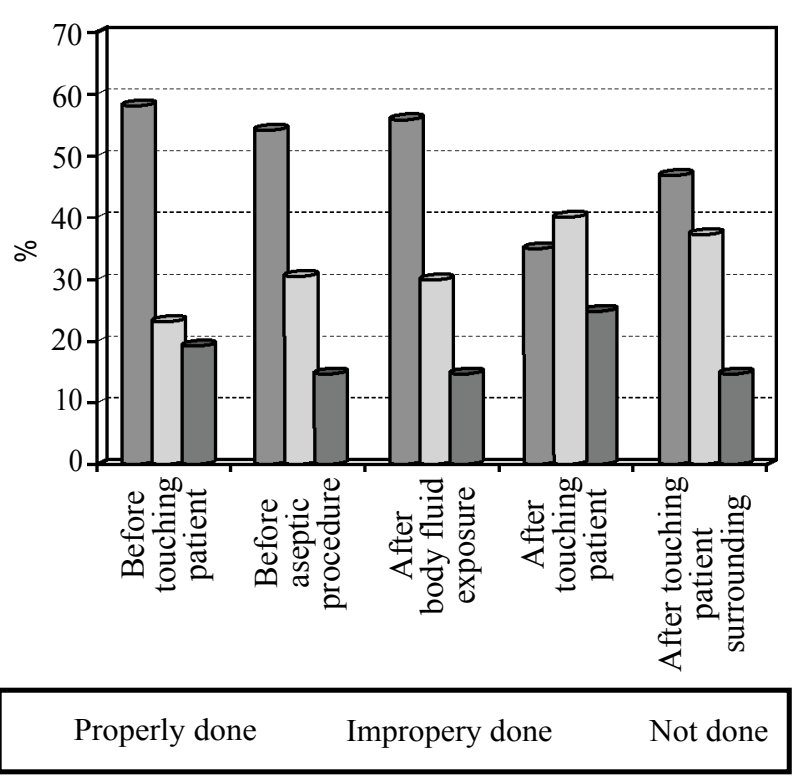

Fig. (1): Nurse hand hygiene practice in neonatal ICU.

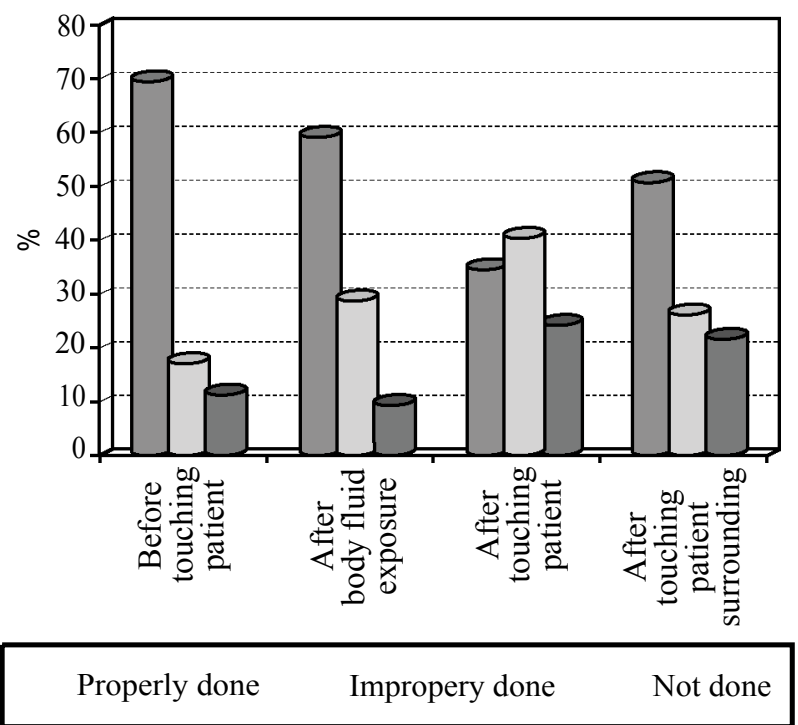

Fig. (2): Physicians hand hygiene practice in neonatal ICU. 


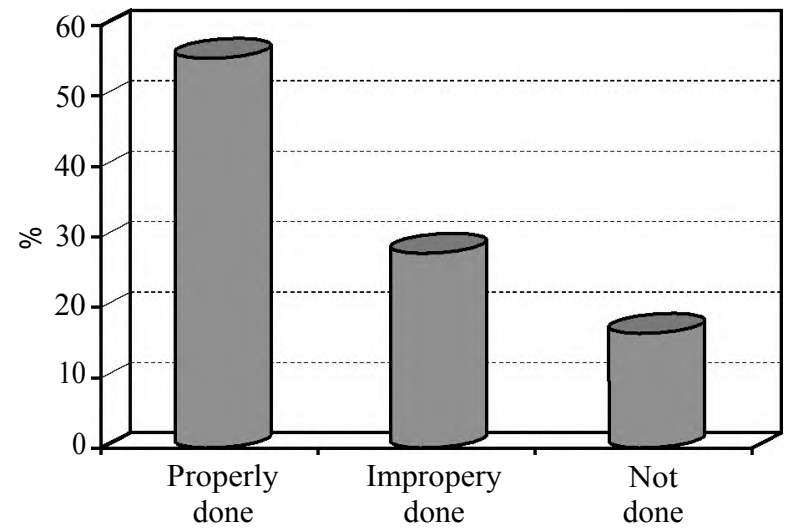

Fig. (3): Physicians hand rub practice before endo-tracheal intubation.

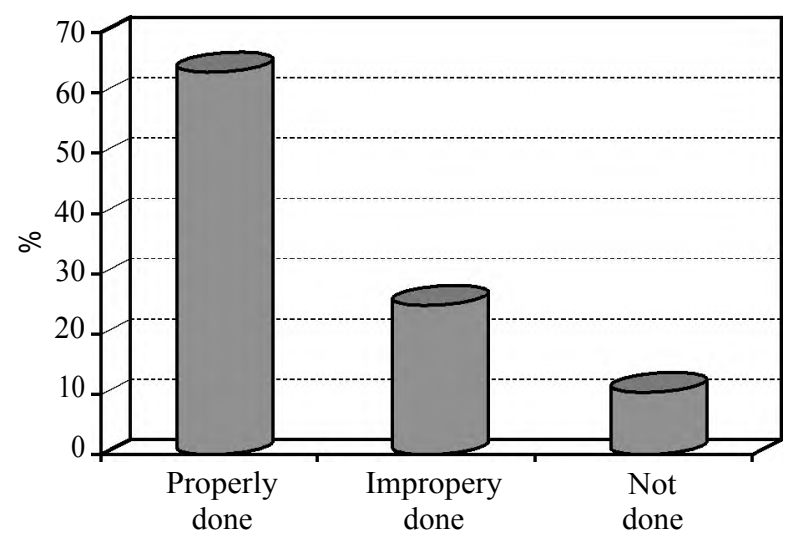

Fig. (4): Physicians hand rub practice before umbilical catheter insertion.

\section{Discussion}

For hand wash, five indications were applied:

1-Before touching patients: The total number of health worker studied for this indication was 289 (119 nurses and 170 physicians). For nurses, hand wash in 69 were properly done $(57.9 \%)$, in 23 were not done (19.3\%) and in 27 were improperly done $(22.6 \%)$ and the main cause of this was insufficient time for hand wash $(<10$ second) with a percentage $55.5 \%$ of causes of improper nurse hand wash before touching patients.

For physicians, in 119 hand wash were properly done $(70 \%)$, in 21 were not done $(12.4 \%)$ and in 30 were improperly done (17.6\%) and the main cause was also insufficient time for hand wash ( $<10$ second) with a percentage $60 \%$ of causes of improper physician hand wash before touching patients.

2- Before aseptic procedures: This indication was applied only for nurses. The total number of nurses studied for this indication was 101, being properly done were in $55(54.4 \%)$, in 15 were not done $(14.8 \%)$ while being improperly done were in $31(30.6 \%)$ and the main cause was in the form of washing hands with water only between different a septic procedures with percentage $45.1 \%$ of causes of improper nurse hand wash before aseptic procedures.

3-After body fluid exposure: The total number studied for this indication was 148 (90 nurses and 58 physicians). For nurses, 51 procedures were properly done $(56.6 \%)$, in 12 hand wash were not done $(13.3 \%)$ and in 27 were improperly done $(30 \%)$ and the main cause was in the form of drying hands in the nurse own gown with percentage $48.1 \%$ of causes of improper nurse hand wash after body fluid exposure.

For physicians, 35 procedures were properly done $(60.3 \%)$, in 6 hand wash were not done $(10.4 \%)$ and in 17 were improperly done (29.3\%) and the main cause was in the form of not rubbing all areas of hands and fingers with percentage $58.8 \%$ of causes of improper physician hand wash after body fluid exposure.

4- After touching patients: The total number studied for this indication was 199 (89 nurses and 110 physicians). For nurses, in 31 the procedures were properly done (34.9\%), in 22 hand wash were not done $(24.7 \%)$ and in 36 procedures were improperly done $(40.4 \%)$ and the main cause was using alcohol for hand wash improperly with a percentage of $50 \%$ of causes of improper nurse hand wash after touching patients.

For physicians, 38 had the procedure were properly done $(34.5 \%)$, in 27 the procedure were not done $(24.5 \%)$ and in 45 hand wash were improperly done $(41 \%)$ and the main cause was using alcohol for hand wash improperly giving a percentage of $62.2 \%$ of causes of improper physician hand wash after touching patients.

5- After touching patients surrounding: The total number studied for this indication was 154 (83 nurses and 71 physicians) for nurses, 39 had the procedure properly done $(46.9 \%)$, in 13 it was not done (15.6\%) and in 31 it was improperly done $(37.3 \%)$ and the main cause was in the form of insufficient time for hand wash $(<10$ second) with percentage $45 \%$ of causes of improper nurse hand wash after touching patients surrounding.

For physicians, 36 had the procedure properly done $(50.7 \%)$, in 16 hand wash not done $(22.5 \%)$ and in 19 it was improperly done $(26.7 \%)$ and the main cause was using alcohol for hand wash im- 
properly with percentage $47.3 \%$ of causes of improper physician hand wash after touching patients surrounding.

For hand rub (done by physicians only), two indications were applied in this study, they were:

1-Endo-tracheal intubation: The total number studied for this indication was 119 . It was properly done in $66(55.4 \%)$, in 20 were not done $(16.8 \%)$ and in 33 were improperly done $(27.7 \%)$ and the main cause was insufficient time for hand rub $(<2$ min.) with percentage $39.3 \%$ of causes of improper physician hand rub before endo-tracheal intubation.

2- Umbilical catheter insertion: The total number studied for this indication was 108. Properly done procedure were in 69 cases $(63.8 \%)$, in 12 were not done $(11.1 \%)$ and in 27 were improperly done $(25 \%)$ and the main cause was in the form of not doing hand rubbing up to elbow with percentage $40.7 \%$ of causes of improper physician hand rub before umbilical catheter insertion.

\section{Conclusion:}

Hand wash was not done properly due to many causes but the most important causes were insufficient time for hand wash $(<10$ sec.), washing hands with water only, not rubbing all areas of hands and fingers and use of alcohol improperly.

For hand rub, it was not done properly due to many causes but the most important causes were insufficient time for hand rub $(<2 \mathrm{~min}$.), hand rubbing not done up to elbow and white coat recontaminate arms after hand rub.

\section{Recommendations:}

- When washing hands with soap and water, wet hands with water and apply the amount of product necessary to cover all surfaces. Rinse hands with water and dry thoroughly with a single-use towel.

- Sufficient time must be taken for hand wash (10$15 \mathrm{sec}$.) and hand rub (2min.) when they are indicated.

- Use towel to turn off tap/faucet. Dry hands thoroughly using a method that does not recontaminate hands. Make sure towels are not used multiple times or by multiple people.

- When hand rub is indicated, the hands should be higher than the arms at all times to avoid recontamination of the hands by water from the elbows.

- White coat should not be touching the arms after hand rub to avoid recontamination.
- The use of gloves does not replace the need for hand hygiene by either handrubbing or handwashing.

- Wear gloves when it can be reasonably anticipated e.g. contact with blood or other potentially infectious materials, mucous membranes, or nonintact skin will occur.

- Remove gloves after caring for a patient. Do not wear the same pair of gloves for the care of more than one patient.

- When wearing gloves, change or remove gloves during patient care if moving from a contaminated body site to another body site.

\section{References}

1- DUCEL G., FABRY J., NICOLLE L., GIRARD R., PERRAUD M., PRUSS A., SAVEY A., TIKHOMIROV E. THURIAUX M. and VANHEMS P.: Prevention of hospital-acquired infections, apractical guide, 2nd Edition, WHO/CDS/CSR/EPH/2002. 12, 2002.

2- TEARE L., COOKSON B. and STONE S.: Hand hygiene use alcohol hand rubs between patients: They reduce the transmission of infection. British Medical Journal, 323 (7310): 411-2, 2001.

3- PESSOA-SILVA C.L., DHARAN S., HUGONNET S., et al.: Dynamics of bacterial hand contamination during routine neonatal care Infection Control and Hospital Epidemiology, 25: 192-7, 2004

4- FOCA M., JAKOB K., WHITTIER S., et al.: Endemic Pseudomonas aeruginosa infection in a neonatal intensive care unit. New England Journal of Medicine, 343 (10): 695-700, 2000.

5- PRATT R.J., PELLOWE C.M., WILSON J.A., et al.: national evidence based guidelines for preventing health care associated infections in NHS hospitals in England. Journal of Hospital Infection, 65 (Suppl 1): S1-S64, 2007.

6- POSAFY-BARBE K.M., ZERR D.M. and PITTET D.: Infection Control in pediatrics Lancet Infect Disease, January, 8: p. 19-3 1, 2008.

7- LARSON E.L., CIMIOTTI J., HAAS J., PARIDES M., NESIN M., DELLA-LATTA P. and SAIMAN L.: Effect of antiseptic handwashingvs alcohol sanitizer on health care-associated infections in neonatal intensive care units. Arch. Pediatr. Adolesc. Med., 159: 377-83, 2005.

8- WIDMER A.F. : Replace hand washing with use of a waterless alcohol hand rub, Clinical Infectious Diseases. 31 (1): 136-43, 2000.

9- FENDLER E.J., ALI Y., HAMMOND B.S., LYONS M.K., KELLEY M.B. and VOWELL N.A.: The impact of alcohol hand sanitizer use on infection rates in an extended care facility. American Journal of Infection Control, 30 (4): 226-33, 2002 


\section{تدقيق إكلينيكى لنظافة آيلى مقلمى الخلدمة بوحلدة رعاية الآطفال

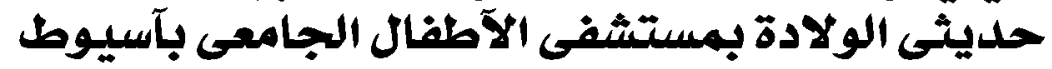

تعتبر نظافة الآيدى آسهل الطرق وآكثرها فاعلية لمنع إنتقال الجراثيم والعدوى المكتسبة من المستشفيات. إن نظافة الآيدى تعتبر آهم

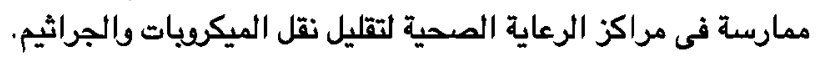

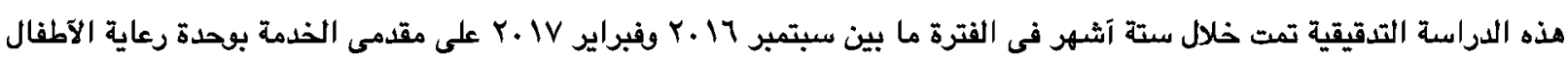

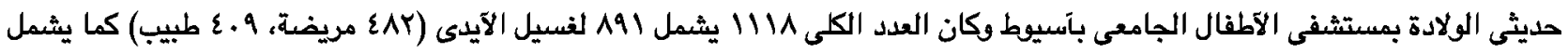

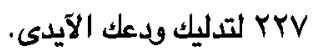

بالنسبة لفسيل الآيدى هناك خمس دواعى تم تطبيقها في هذه الرسالة:

$$
\text { ا ب - قبل ملامسية المرضى. }
$$

ب- قبل عمليات التطهير.

ب- بعد التعرض لسوائل الجسم.

ع - بعد ملامسة المرضى. - بعل

0 - بعد ملامسية الآثياء المحيطة بالمرضى.

بالنسبة لدعك وتدليك الآيدى هناك داعيان تم تطبيقهما في هذه الرسالة:

ا- قبل تركيب آنبوبة داخل القصبة الهوائية. r- قبل تركيب قسطرة السرة. 